\title{
NEMATÓIDES DAS GALHAS DIFICULTAM A PRODUÇÃO DE MUDAS DE JABORANDI (1)
}

\author{
RUBENS R. A. LORDELLO $\left({ }^{2}\right)$, ANA INES LUCENA LORDELLO $\left({ }^{3}\right)$ \\ e MARIO G. R. DONALISIO $\left({ }^{4}\right)$
}

O jaborandi (Pilocarpus microphyllus Starf.) é uma planta medicinal explorada no Maranhão (CORREIA, 1969), por meio da coleta de folhas em plantas da vegetação natural, para obtenção de pilocarpina, alcalóide utilizado no tratamento do glaucoma (YOUNGKEN, 1950), doença que freqüentemente leva à cegueira.

Para eliminar os problemas do extrativismo, a Merck Indústrias Químicas S.A. iniciou, em 1980, em sua fazenda (São Luis, MA), a produção de mudas para o plantio em larga escala, racionalizando seu cultivo. Foram preparadas 160.000 mudas em sacos plásticos, deixados em condições naturais, à meia sombra de folhas de palmeiras, até atingirem cerca de $10 \mathrm{~cm}$ de altura, quando apresentaram crescimento desuniforme, amarelecimento e, finalmente, mais de 90\% morreram. nas (SP).

(1) Recebido para publicação em 28 de agosto de 1985.

(2) Seção de Microbiologia Fitotécnica, Instituto Agronômico (IAC), Caixa Postal 28, 13001 Campi-

(3) EMBRAPA/Seção de Microbiologia Fitotécnica, IAC.

(4) Seção de Plantas Aromáticas e Fumo, IAC.

(5) Com bolsa de suplementação do CNPq. 
O exame dos reduzidos sistemas radiculares mostrou a presença de galhas, de onde foram extraídas fêmeas de nematőides da espécie Meloidogyne incognita (Kofoid \& White, 1919) Chitwood, 1949, classificada como raça 1 pelo teste de hospedeiros diferenciais (TAYLOR \& SASSER, 1978).

Como as mudas foram plantadas em terra sem tratamento e irrigadas com água de um riacho, para estabelecer a causa da infestação foi realizado um experimento que consistiu em semear tomate em vasos, com os seguintes tratamentos: da cidade;

a) terra tratada com brometo de metila e irrigada com água de torneira

b) terra tratada e água do riacho filtrada;

c) terra tratada e água do riacho;

d) terra não tratada e água da cidade.

Somente as raizes dos tomateiros do tratamento d) apresentaram infestação de $M$. incognita, mostrando que os nematóides que infestaram as mudas vieram com a terra.

A alta suscetibilidade do jaborandi à $M$. incognita raça 1 , aqui relatada, assim como à $M$. arenaria (SILVA, 1982), exige a adoção de medidas preventivas de controle, especialmente o uso de terra isenta desses nematóides na produção de mudas.

Termos de indexação: nematóide das galhas; Meloidogyne incognita, ocorrência; jaborandi, Pilocarpus microphyllus Starf., planta medicinal, perdas.

\section{SUMMARY \\ ROOT-KNOT NEMATODES RESTRAINS THE SEEDLING PRODUCTION OF JABORANDI}

The jaborandi (Pilocarpus microphyllus Starf.) is a medical plant found in Maranhão State, Brazil, which is the natural source of the drug pilocarpine used to treat glaucoma, a disease that frequently causes blindness. The leaves used for extraction of pilocarpine are presently collected from plants that grow naturally. Instead of pure extractive exploitation it has been tried the cultivation of this plant in order to improve and increase the production. Nevertheless, $90 \%$ of 160,000 young seedlings were lost due to the infestation of Meloidogyne incognita race 1. Research showed the soil as the source of infestation.

Index terms: root-knot nematode, Meloidogyne incognita, occurrence, jaborandi, Pilocarpus microphyllus Starf., medical plant. 


\section{REFERÊNCIAS BIBLIOGRÁFICAS}

CORREIA, M.P. Dicionário das plantas áteis do Brasil e das ex6́ticas cultivadas. Rio de Janeiro, Ministerio da Agricultura/IBDF, 1969. v.4.

SILVA, G.S. Meloidoginose do jaborandi (Pilocarpus microphyllus Starf.). Fitopatologia Brasileira, Brasilia, 7(1):121-123, 1982.

TAYLOR, A.L. \& SASSER, J.N. Biology identification and control of root-knot nematode (Meloidogyne species). Raleigh, North Carolina State Univ., Dep. of Plant Pathol., 1978. 111p.

Y.UNGKEN, H.W. Textbook of pharmacognosy. 6.ed. New York, McGraw-Hill, 19Ju. $1063 \mathrm{p}$. 